Article

\title{
Altered Envelope Structure and Nanomechanical Properties of a C-Terminal Protease A-Deficient Rhizobium leguminosarum
}

\author{
Dong Jun, Ubong Idem and Tanya E. S. Dahms * \\ Department of Chemistry and Biochemistry, University of Regina, Regina, SK S4S 0A2, Canada; \\ andrea.jun.dong@gmail.com (D.J.); ubidem@gmail.com (U.I.) \\ * Correspondence: tanya.dahms@uregina.ca; Tel.: +1-306-585-4246
}

Received: 17 July 2020; Accepted: 13 September 2020; Published: 16 September 2020

\begin{abstract}
Background: Many factors can impact bacterial mechanical properties, which play an important role in survival and adaptation. This study characterizes the ultrastructural phenotype, elastic and viscoelastic properties of Rhizobium leguminosarum bv. viciae 3841 and the C-terminal protease A $(\operatorname{ctp} A)$ null mutant strain predicted to have a compromised cell envelope; (2) Methods: To probe the cell envelope, we used transmission electron microscopy (TEM), high performance liquid chromatography (HPLC), mass spectrometry (MS), atomic force microscopy (AFM) force spectroscopy, and time-dependent AFM creep deformation; (3) Results: TEM images show a compromised and often detached outer membrane for the ctpA mutant. Muropeptide characterization by HPLC and MS showed an increase in peptidoglycan dimeric peptide (GlcNAc-MurNAc-Ala-Glu-meso-DAP-Ala-meso-DAP-Glu-Ala-MurNAc-GlcNAc) for the $\operatorname{ctp} A$ mutant, indicative of increased crosslinking. The $\operatorname{ctp} A$ mutant had significantly larger spring constants than wild type under all hydrated conditions, attributable to more highly crosslinked peptidoglycan. Time-dependent AFM creep deformation for both the wild type and $\operatorname{ctp} A$ mutant was indicative of a viscoelastic cell envelope, with best fit to the four-element Burgers model and generating values for viscoelastic parameters $\mathrm{k}_{1}, \mathrm{k}_{2}, \eta_{1}$, and $\eta_{2} ;$ (4) Conclusions: The viscoelastic response of the $\operatorname{ctp} A$ mutant is consistent with both its compromised outer membrane (TEM) and fortified peptidoglycan layer (HPLC/MS).
\end{abstract}

Keywords: atomic force microscopy; cell envelope; C-terminal protease; force spectroscopy; Rhizobium leguminosarum; viscoelasticity

\section{Introduction}

Mechanical changes arising from the environment have been linked to microbial gene expression, physiology and pathogenesis, and bacterial mechanical properties are integral to both their survival and adaptation [1]. The microbial envelope is viscoelastic [2], exhibiting both elastic and viscous properties, with enough flexibility to accommodate growth and division but sufficiently rigid to resist turgor pressure and maintain a specific shape [3]. While an elastic material can recover its shape following instantaneous deformation, a viscous one responds with a flow rate [4], and thus a viscoelastic material can both store and dissipate mechanical energy in response to stress [5].

The mechanical properties of the bacterial cell envelope are defined by its biochemical composition and interactions between the various components [6]. The cell envelope in Gram-negative bacteria is composed of three principal layers, the inner membrane, periplasm, and outer membrane $[7,8]$. The inner membrane (IM), which surrounds the bacterial cytosol, is composed of a phospholipid bilayer that houses many proteins associated with energy production, lipid biosynthesis, protein secretion, 
and transport $[9,10]$. The periplasm is more viscous than the cytoplasm [11], with densely packed soluble proteins [12] and the peptidoglycan polymer which is composed of an alternating chain of $\mathrm{N}$-acetyl glucosamine (GlcNAc) and N-acetyl muramic acid (MurNAc) covalently linked by short peptide chains [13]. The inner leaflet of the asymmetric outer membrane is composed of lipid A (two glucosamine subunits covalently linked to six or seven acyl chains and phosphate groups) and the outer leaflet contains lipopolysaccharide (LPS) [14]. LPS is lipid covalently linked to a core polysaccharide, consisting of heptose, hexoses, and 3-deoxy-D-manno-octulosonic (2-keto-3-deoxyoctonic) acid (Kdo) [15], and O-antigen composed of repetitive oligosaccharide subunits extending outward from the outer membrane [16]. Crucial for osmotic adaptation $[17,18]$ are outer wall cyclic $\beta$-glucans, composed of a D-glucose backbone with 5-40 glucopyranosyl residues linked together by $\beta-1,2-, \beta-1,3-$, or $\beta-1,6$-glycosidic bonds [19].

All layers in the cell envelope contribute to the overall mechanical response, which includes instantaneous elastic deformation, delayed elastic deformation, and viscous flow under an applied external force [6]. The periplasmic cell wall confers rigidity, maintains cell shape, and is the major contributor to elastic properties of the bacterial cell envelope [20,21], with peptidoglycan playing a significant role [22]. The viscoelastic properties of the inner membrane depend on its chemical composition, intrinsic tension as a function of differential packing, and adaptation to physical variables, such as temperature, pressure, and $\mathrm{pH}$ [23]. Membrane domains of fluidly ordered phospholipids and other membrane components impact bilayer viscosity [24-26], where the liquid phase is less stiff than the gel phase [27]. The softer outer membrane contributes less elasticity than the periplasmic peptidoglycan layer [21], but its viscoelasticity contributes to the overall mechanical response, with viscous relaxation in Escherichia coli attributed to reorganization of membrane components [28].

Atomic force microscopy (AFM) has been used to measure the mechanical properties of the bacterial cell surface under physiological conditions, revealing that the bacterial cell envelope is extensible, flexible, elastic and viscous $[4,6,22,29,30]$. The viscoelastic response induced by an external force on the cell surface can be tracked using force spectroscopy, but interpretation of force curves acquired from Gram-negative bacteria is nontrivial [4]. Vadillo-Rodriguez et al. developed a model combining elastic and viscous elements to describe the deformation of the bacterial cell envelope as a time-dependent creep response under constant external loads [6]. Based on one of the simplest models to predict creep response [2], it consists of an elastic spring combined in series with a parallel spring and dashpot. Their model successfully interpreted the mechanical behavior of the cell envelope of Pseudomonas aeruginosa PAO1 in response to an applied constant compressive force [6] and three viscoelastic parameters, $\mathrm{k}_{1}, \mathrm{k}_{2}$, and $\eta_{2}$, were measured for Gram-negative (E. coli) and Gram-positive (Bacillus subtilis) bacteria [22]. Both studies reveal two elastic processes contributing to the mechanical response of the bacterial cell envelope: an instantaneous elastic deformation of the cell envelope $\left(k_{1}\right)$ and a delayed elastic creep deformation characterized by $k_{2}$ and $\eta_{2}$. Lu et al. further modified the model to interpret the viscoelastic behavior of the bacterial cell envelope in response to antimicrobial peptides, showing that increased membrane permeability can alter viscoelastic properties [30].

Here we determine the mechanical properties of the Rhizobium leguminosarum cell envelope and evaluate the influence of a C-terminal protease A $(\operatorname{ctp} A)$ mutation on its mechanics. Gram-negative free-living rhizobia are faced with a dynamic and unpredictable soil environment [31,32] prior to forming root nodules [33], requiring substantial adaptation in which the cell envelope plays a significant role. Carboxyl terminal protease (Ctp) cleaves a number of amino acid residues from the carboxyl terminal end of protein precursors during post-translational modification [34]. The first homolog of Ctp in the bacterial kingdom was discovered in E. coli and designated as tail-specific protease (Tsp), also known as Prc. The prc deletion mutant was defective in processing the penicillin-binding protein 3 (PBP3), exhibited thermosensitive growth in salt-free media, had a filamentous morphology, reduced cell wall integrity, and caused leaky membranes [34]. Disruption of prc increases antibiotic susceptibility [35] and reduces the level of bacteremia in human sera, increasing susceptibility for serum killing of the pathogenic E. coli strain RS218 [36], thus linking Ctp to the regulation of cell morphology, 
cell survival, and host evasion. The R. leguminosarum ctpA null mutant grows in complex liquid medium but not complex semi-solid agar and has increased susceptibility to detergent, indicating a compromised cell envelope [37]. We found the $\operatorname{ctp} A$ mutant incapable of developing fully mature biofilms, consistent with its altered surface ultrastructure, greater roughness, and stronger adhesion to hydrophilic surfaces [38]. We since identified nine periplasmic solute-binding components of ABC transporters with altered abundance in the $\operatorname{ctp} A$ mutant [39], consistent with $C t p A$ as a periplasmic enzyme [34]. Thus, we hypothesized that a penicillin binding protein (PBP) is a CtpA substrate, and its absence would alter the mechanical properties of the rhizobial cell envelope by changing the peptidoglycan structure. This study not only offers insight into the $\operatorname{ctp} A$ mutation, but helps develop an understanding of a complex microbial interface and the intricate relationship between rhizobial cell envelope structure, dynamics, and function.

\section{Materials and Methods}

\subsection{Bacterial Strains, Plasmids, and Media}

R. leguminosarum biovar viciae 3841, a spontaneous streptomycin-resistant derivative of R. leguminosarum bv. viciae strain 300 [40], served as the wild-type strain used in this study. The $\operatorname{ctp} A$ mutant strain 3845 was prepared by Gilbert et al. [37] and strains of R. leguminosarum were cultured in Vincent's minimal medium (VMM) [41] with $10 \mathrm{mM}$ mannitol as a carbon source. Media was supplemented with appropriate antibiotics $(\mu \mathrm{g} / \mathrm{mL})$ : streptomycin (500); neomycin (100); tetracyclineD (5). Unless otherwise stated, all materials were purchased from Sigma Aldrich (Oakville, ON, Canada).

\subsection{Isolation of Peptidoglycan}

Peptidoglycan was prepared as described by Pisabarro et al. [42]. Briefly, cell cultures (500 mL), initiated from a $10 \mathrm{~mL}$ starter culture, were grown $\left(\mathrm{OD}_{600} \sim 0.6\right)$ and quickly cooled in an ice/water bath. Cells were harvested by centrifugation $\left(20 \mathrm{~min}, 8000 \times g, 4{ }^{\circ} \mathrm{C}\right)$, resuspended in $2 \mathrm{~mL} \mathrm{VMM}$ buffer $\left(5.74 \mathrm{mM} \mathrm{K}_{2} \mathrm{HPO}_{4}, 7.35 \mathrm{mM} \mathrm{KH} \mathrm{PO}_{4}, 5.93 \mathrm{mM} \mathrm{KNO}, 0.04 \mathrm{mM} \mathrm{FeCl} 3 \cdot 6 \mathrm{H}_{2} \mathrm{O}, 1 \mathrm{mM} \mathrm{MgSO} \cdot 7 \mathrm{H}_{2} \mathrm{O}_{\text {, }}\right.$ $0.46 \mathrm{mM} \mathrm{CaCl}_{2} \cdot 6 \mathrm{H}_{2} \mathrm{O}$ ) which was isotonic to the VMM broth, the suspension boiled in sodium dodecyl sulfate (SDS, 8\%, $4.5 \mathrm{~mL}$ ) for $60 \mathrm{~min}$, kept at room temperature (RT) overnight and boiled again for $60 \mathrm{~min}$. The suspension was ultracentrifuged $(100,000 \times g, 45 \mathrm{~min})$, the pellet washed with hot deionized water $(5 \times)$, high molecular weight glycogen removed by treatment with $200 \mu \mathrm{g}$ of $\alpha$-amylase $\left(1 \mathrm{~h}\right.$ at $\left.37^{\circ} \mathrm{C}\right)$ and covalently attached proteins removed with protease $\left(200 \mu \mathrm{g}, 1 \mathrm{~h}, 60^{\circ} \mathrm{C}\right)$. The insoluble peptidoglycan was recovered by ultracentrifugation $(100,000 \times g, 30 \mathrm{~min})$ and lyophilized overnight.

\subsection{Muropeptide Structural Analysis}

Muropeptides were prepared as described by Pisabarro et al. [42]. Briefly, dry peptidoglycan was diluted $(2 \mathrm{mg} / \mathrm{mL})$ in $25 \mathrm{mM}$ sodium phosphate $(\mathrm{pH} 6.8)$, treated with lysozyme $(20 \mu \mathrm{g} / \mathrm{mL}$; $\left.37^{\circ} \mathrm{C} \mathrm{O} / \mathrm{N}\right)$, followed by boiling $\left(10 \mathrm{~min}, 100{ }^{\circ} \mathrm{C}\right)$, and centrifugation $(19,000 \times g, 10 \mathrm{~min})$ to remove insoluble material. Supernatant was mixed with the same volume of sodium borate buffer ( $0.5 \mathrm{M}$; pH 9.0) and incubated (RT, $30 \mathrm{~min}$ ) with excess borohydride, neutralized with $20 \%$ phosphoric acid (1/20 volume) to a $\mathrm{pH}$ between 4 and 5 , and samples stored at $-20^{\circ} \mathrm{C}$. Muropeptides were separated on a reversed-phase column (3.5 $\mu \mathrm{m}$ ZORBAX, 300SB-C18, $150 \times 4.6 \mathrm{~mm}$, Agilent, Santa Clara, California, United States) using an Agilent high performance liquid chromatography (HPLC) system consisting of a Hewlett Packard 1050 series pump and a UV detector. Initial separation used gradient elution from $100 \%$ buffer $\mathrm{A}\left(\mathrm{H}_{2} \mathrm{O}\right.$ with $0.1 \%$ TFA $\left.v / v\right)$ to $100 \%$ Buffer B (acetonitrile with $0.1 \%$ TFA v/v) over 120 min at a flow rate of $1 \mathrm{~mL} / \mathrm{min}$ and conditions were optimized to separate all the rhizobial muropeptides in a single run (Figure S1). The muropeptide fractions were detected at $205 \mathrm{~nm}$, collected at full width at half maximum (FWHM), and quantified by integration of their peak area using ChemStation (Agilent). 
The total peak area from all fractions, excluding the salt fraction, was normalized to $100 \%$, and the percent total area of each fraction determined.

Muropeptide fractions were analyzed on an $\mathrm{AB} 4800$ matrix-assisted laser desorption/ionization time-of-flight (MALDI-TOF) mass spectrometer (Applied Biosystems, LLC, Frederick, MD, USA) [43]. For MALDI matrix deposition, $10 \mathrm{mg} / \mathrm{mL}$ 2,5-dihydroxybenzoic acid was prepared in methanol/water $(1: 1 \mathrm{v} / \mathrm{v})$ with $50 \mathrm{mM}$ of $\mathrm{NaCl}$, to ensure that sodiated adducts $[\mathrm{M}+\mathrm{Na}]^{+}$were the predominant ions. Matrix solution $(0.8 \mu \mathrm{L})$ was deposited onto a 384-well plate (Opti-TOF insert, Applied Biosystems), followed by the application of the muropeptide sample ( $1.0 \mu \mathrm{L}$ in $5 \%$ acetonitrile). The plate was dried under ambient conditions, loaded into the instrument operated with the Applied Biosystems 4000 Series Explorer program (Version 3.5.3) and data collected in the positive ion reflection mode. A six-peptide reference mixture was used as an external mass calibration standard prior to data acquisition. The ion extraction delay time was set to be $500 \mathrm{~ns}$, and 1000 laser shots were collected and averaged for each spectrum.

\subsection{Transmission Electron Microscopy (TEM) Imaging}

Single colonies of Rhizobium leguminosarum wild type 3841 and ctpA mutant 3845 from a TY agar plate, supplemented with $20 \mathrm{mM}$ mannitol were isolated and grown in $5 \mathrm{~mL}$ TY broth medium at $30^{\circ} \mathrm{C}$ to an $\mathrm{OD}_{600}$ of 0.6 , centrifuged $(1000 \times g$ for $5 \mathrm{~min})$ and cell pellets resuspended in VMM buffer. Cells were fixed ( $3.7 \%$ formaldehyde and $0.2 \%$ Triton X-100 in VMM buffer; $20 \mathrm{~min}, 30^{\circ} \mathrm{C}$ ), rinsed with VMM buffer, and transported to the transmission electron microscopy (TEM) imaging facility (University of Calgary) where samples were fixed $(1 \mathrm{~h})$ with $1 \%$ osmium tetroxide, rinsed, substituted with $50 \%$, $75 \%, 95 \%$, and 100\% acetone, embedded with JEMBED liquid plastic (Canemco, Lakefield, Québec, Canada), and small blocks of embedded bacteria cut with an ultramicrotome (Leica ultracut). Ultrathin sections were then positively stained with uranyl acetate and lead citrate for TEM (H-7650, Hitachi, Tokyo, Japan) imaging at $60 \mathrm{keV}$.

\subsection{AFM Imaging and Force Data Acquisition}

Cell pellets, as prepared for TEM, were resuspended in buffer prior to immobilization. Topographic features of pea leaves, initially tested as natural substrates for live R. leguminosarum, were not discernable from rhizobia in AFM images, so live, actively growing samples, were prepared on dialysis tubing using the method adapted from our previous work on A. nidulans [44]. Briefly, sterilized dialysis tubing was incubated for $24 \mathrm{~h}$ in R. leguminosarum culture and then rinsed with VMM buffer to remove non-adhering rhizobial cells. During imaging, media was fed to the rhizobia through the filter paper inserted in the dialysis tubing to maintain cell viability. Images are representative of rhizobial cells from three biological replicates, at least 10 images per replicate and a minimum of three cells per image.

Preliminary experiments probing the mechanical properties of $R$. leguminosarum wild type 3841 and $\operatorname{ctp} A$ mutant 3845 used a commercial AFM (TopoMetrix Explorer 2000 AFM, Veeco Instruments, Santa Barbara, CA) equipped with a dry AFM scanner (Model No. 400006). Force curves were acquired using V-shaped silicon nitride tips (Model MLCT-EXMT-A1, Veeco) having a nominal spring constant of $0.05 \mathrm{~N} / \mathrm{m}$. Force-indentation experiments were carried out using AFM force spectroscopy at room temperature. The spring constant of the cantilever was determined directly prior to force curve acquisition according to Cleveland and coworkers [45]. The AFM tip approached the sample at $10 \mu \mathrm{m} / \mathrm{s}$ until it reached a preset position and then retracted. The slopes of the force curves were recorded and converted into the bacterial spring constant according to the equation:

$$
\mathrm{k}_{\mathrm{b}}=\frac{\mathrm{sk}_{\mathrm{c}}}{1-\mathrm{s}}
$$

where $\mathrm{s}$ is the slope of the force curve and $\mathrm{k}_{\mathrm{c}}$ is the spring constant of the cantilever. Surface adhesion values were measured from the point at which the AFM tip retracts from the sample surface to 
zero adhesive force. The force curves acquired from the experiments were processed with SPMLab software 5.01 .

\subsection{AFM Creep Experiments}

Bacterial cells resuspended in media $(100 \mu \mathrm{L})$ were deposited onto PLL coated glass coverslips [38], and incubated (30 min, RT). The bacterium-coated glass coverslip was gently rinsed with nanopure water five times to remove excess media and loosely attached bacterial cells in preparation for AFM imaging and force spectroscopy. To rule out a deleterious effect of PLL on rhizobial viability, growth medium was added to the sample and bacterial viability monitored over $24 \mathrm{~h}$, at RT in a separate experiment, during which we observed rhizobia dividing, detaching, and sometimes reattaching to the surface [6].

To determine the viscoelastic responses of R. leguminosarum wild type 3841 and ctpA mutant 3845, AFM (Nanowizard 3, JPK, Berlin, Germany) measurements were carried out at room temperature under nanopure water (resistivity > 18.2 M ) to maximize osmotic pressure (Rodriguez et al., 2008). Live rhizobial cells were first imaged in quantitative imaging mode at low applied force $(<0.5 \mathrm{nN})$ at a scan rate of $0.5 \mathrm{~Hz}$ using silicon nitride V-shaped cantilevers having a pyramid-shaped tip with a typical radius of curvature of $10 \mathrm{~nm}$ (PNP-TR, nominal spring constant $=0.08 \mathrm{~N} / \mathrm{m}$, Nanoworld, Neuchâtel, Switzerland). Prior to force experiments, the cantilever spring constant was determined using the thermal fluctuation method [46]. To determine the elastic and viscous contributions to the mechanical properties, three force curves were collected from the top center of 5-10 single cells from at least three biological replicates, with a constant tip approach rate $(1 \mu \mathrm{m} / \mathrm{s})$ set to a predetermined loading force value $(2,4,6$, and $10 \mathrm{nN})$. Once the loading force was reached, it was held constant for $10 \mathrm{~s}$ during creep experiments. The fast elastic response and delayed elastic response of the cell envelope, corresponding to creep deformation, were described by the four element Burgers model [30]:

$$
Z(t)=\frac{F_{0}}{k_{1}}+\frac{F_{0}}{k_{2}}\left(1-e^{-\frac{k_{2}}{\eta_{2}} t}\right)+\frac{F_{0}}{\eta_{1}} t ;
$$

where $Z(t)$ is the total deformation of the material at time $t, F_{0}$ is the applied force, $\eta_{1}$ and $\eta_{2}$ are dashpot viscosities for which $k_{1}$ and $k_{2}$ are parallel spring constants. When a constant force is applied to the system at time $t$, the deformation can be described as:

$$
\mathrm{Z}(t)=Z_{s}+Z_{d}=\frac{F_{0}}{k_{1}}+\frac{F_{0}}{\eta_{1}} t
$$

where $Z_{S}$ and $Z_{d}$ are the deformation of the spring and dashpot, respectively. The best-fit values of $k_{1}$, $k_{2}, \eta_{1}$, and $\eta_{2}$, describing the mechanical response of the cell, were obtained by nonlinear regression in Excel (Microsoft office 2010). Differences in parameters between the wild type and $\operatorname{ctp} A$ mutant $R$. leguminosarum were assessed with a paired Student's t-test.

\section{Results}

\subsection{Cell Envelope Ultrastructure}

Prior evidence of cell envelope disruption for the $\operatorname{ctp} A$ mutant came from AFM images of fixed cells [38]. Since AFM-based force spectroscopy and creep deformation experiments necessitate live cells, it was important to first test if live ctpA mutant cells (Figure 1C,D) had less well ordered surfaces than wild type (Figure 1A,B), like their fixed counterparts. This was the case, as evidenced by the difference in topographic height range $(z$, color scale $B, D)$ and subunit size $(x, y)$. The nonlinear response often observed for Gram-negative bacteria [6] was rarely observed in the force curves of wild type cells in this study (Figure 1E). To further pinpoint specific regions of the cell envelope associated with the cell surface architectural changes, transmission electron microscopy (TEM) was used to image 
R. leguminosarum. Consistently, TEM images showed the $\operatorname{ctp} A$ mutant to have a significantly greater number of cells (low resolution images on left) with detached outer membranes (red arrows on low and high resolution images), compared to wild type (Figure 2).
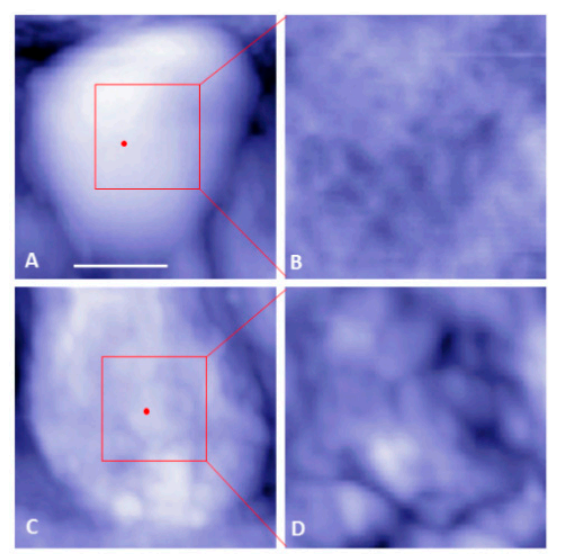

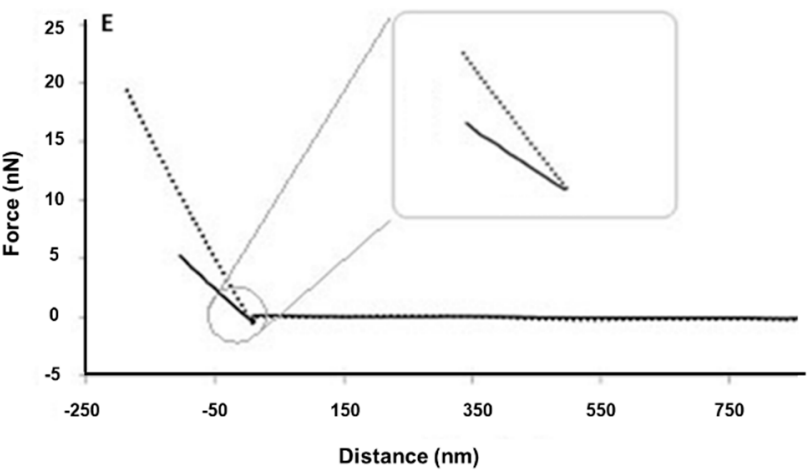

Figure 1. Representative atomic force microscopy (AFM) topography images and corresponding force curves of live Rhizobium leguminosarum bv. viciae 3841 (wild type, top row) and 3845 (ctpA mutant, bottom row). Shown are low $(\mathbf{A}, \mathbf{C})$ and high $(\mathbf{B}, \mathbf{D})$ resolution AFM images of the live wild type $(\mathbf{A}, \mathbf{B})$ and $\operatorname{ctp} A$ mutant $(\mathbf{C}, \mathbf{D})$ rhizobia. Bar for $\mathrm{A}$ and $\mathrm{C}$ is $500 \mathrm{~nm}$. Red dots on $\mathrm{A}, \mathrm{C}$ indicate the approximate locations at the top center of the live cells, for collecting corresponding force approach curves (E) with solid (wild type) and dashed (ctpA mutant) lines, and subsequent creep experiments.

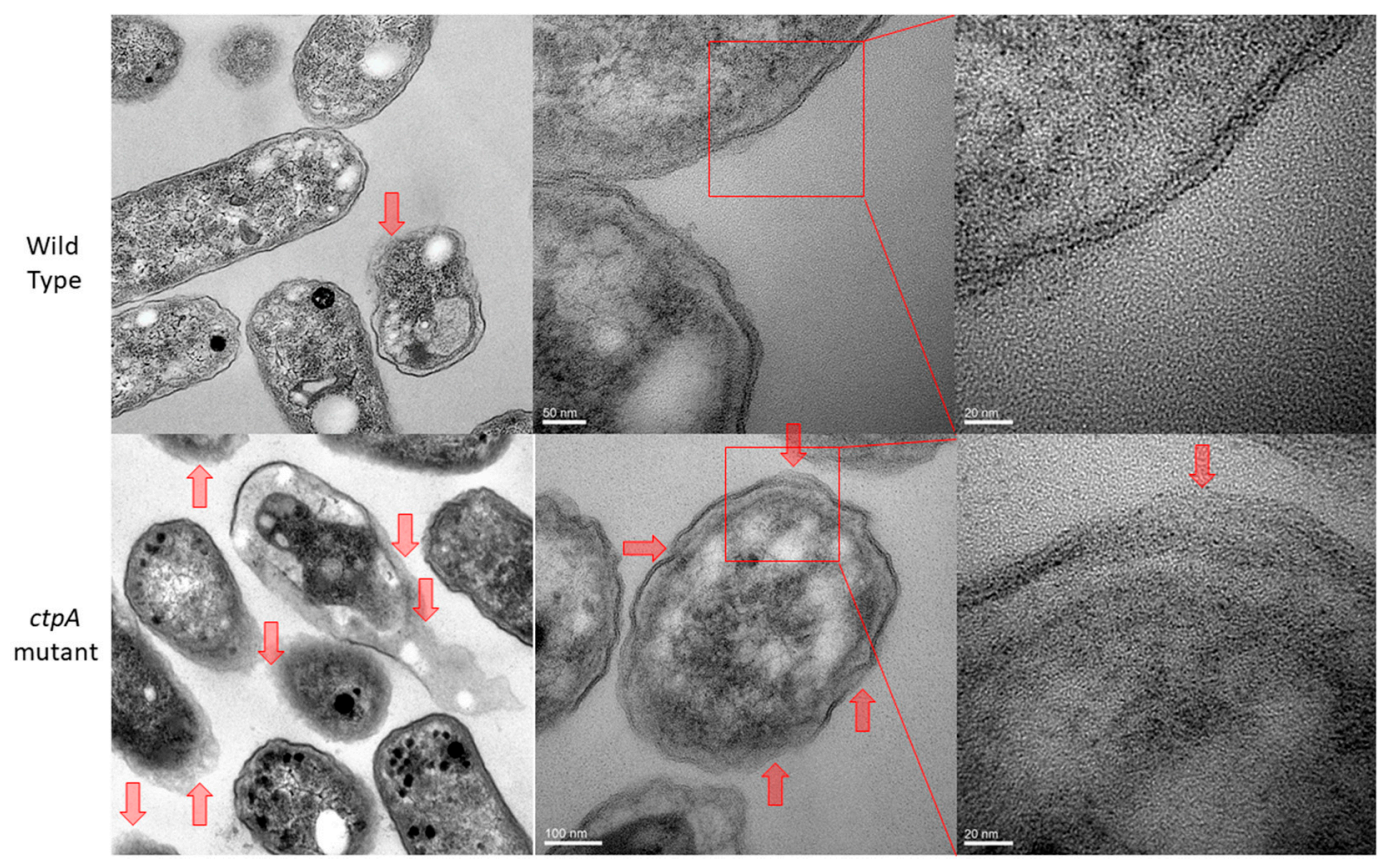

Figure 2. TEM images of Rhizobium leguminosarum bv. viciae 3841 (wild type, top row), the majority of which show clearly defined inner and outer membranes, and 3845 (ctpA mutant, bottom row). Red arrows indicate detached outer membranes, which are more numerous in the mutant.

\subsection{Muropeptide Composition}

To provide preliminary evidence for the hypothesis that PBPs are target substrates of $c t p A$ in Rhizobium leguminosarum bv. viciae 3841, muropeptide was analyzed. Muropeptides isolated from lysozyme-treated peptidoglycan and purified from the R. leguminosarum wild type and $\operatorname{ctp} A$ mutant strains had identical HPLC profiles (Table S1 and Figure S1), showing that the basic peptidoglycan 
unit was not significantly altered in the mutant. Interestingly, peaks 2,10 , and 11 from the $\operatorname{ctp} A$ mutant strain had significantly larger peak area $(p<0.05, n=10)$ than wild type (Table 1$)$.

Table 1. Structures, molecular masses, and quantities of muropeptides from Rhizobium leguminosarum bv. viciae 3841 and $\operatorname{ctp} A$ mutant 3845 .

\begin{tabular}{|c|c|c|c|c|c|}
\hline \multirow{2}{*}{ Peak } & \multirow{2}{*}{ Proposed Structure } & \multirow{2}{*}{$\begin{array}{c}\text { Observed } \\
m / z\end{array}$} & \multirow{2}{*}{$\begin{array}{c}\text { Calculated } \\
{[\mathrm{M}+\mathrm{Na}]^{+}}\end{array}$} & \multicolumn{2}{|c|}{$\%$ of All Peaks } \\
\hline & & & & Wild Type & $\operatorname{ctpA}$ Mutant \\
\hline 2 & GlcNAc-MurNAc-Ala-Glu-meso-DAP & 893.4 & 893.8 & 2.0 & 2.7 \\
\hline 3 & GlcNAc-MurNAc-Ala-Glu-meso-DAP-Gly & 950.4 & 950.9 & 1.6 & 1.6 \\
\hline 6 & GlcNAc-MurNAc-Ala-Glu-meso-DAP-Ala & 964.5 & 964.9 & 6.2 & 8.3 \\
\hline 10 & $\begin{array}{l}\text { GlcNAc-MurNAc-Ala-Glu-meso-DAP-Ala- } \\
\text { meso-DAP-Glu-Ala-MurNAc-GlcNAc }\end{array}$ & 1816.9 & 1816.8 & 1.3 & 2.4 \\
\hline 11 & $\begin{array}{l}\text { MurNAc-Ala-Glu-meso-DAP-Ala-meso- } \\
\text { DAP-Glu-Ala-MurNAc }\end{array}$ & 1408.7 & 1408.4 & 1.1 & 2.2 \\
\hline 12 & $\begin{array}{l}\text { GlcNAc-MurNAc-Ala-Glu-meso-DAP-Ala- } \\
\text { Ala-meso-DAP-Glu-Ala-MurNAc-GlcNAc }\end{array}$ & 1888.0 & 1887.9 & 2.9 & 3.0 \\
\hline
\end{tabular}

MALDI-TOF mass spectrometry (MS) analysis of the major components (peaks 2, 3, 6, 10, 11, and 12) showed identical mass spectra for corresponding peaks from wild type and ctpA (Figure S2, Table 1), confirming identical muropeptides eluting at the same retention time. Molecular weights (Table 1) indicate a glycan strand with repeating GlcNAc and MurNAc disaccharides, the latter linked to a 3-5 residue peptide (Figure S2). Under our experimental conditions, GluNAc-MurNAc-AlaGlu-mDAP-Ala was the major peptide bridge component for R. leguminosarum bv. viciae 3841. The $\operatorname{ctp} A$ mutation affected the relative amounts of peptidoglycan cross linkers, namely the monomeric and dimeric peptides (GlcNAc-MurNAc-Ala-Glu-meso-DAP, GlcNAc-MurNAc-Ala-Glu-mesoDAP-Ala, and GlcNAc-MurNAc-Ala-Glu-meso-DAP-Ala-meso-DAP-Glu-Ala-MurNAc-GlcNAc), but their structural components were not altered.

\subsection{R. leguminosarum Cell Envelope Elasticity and Spring Constant}

To test the hypothesis that the deletion of $\operatorname{ctp} A$ has an impact on the cell envelope mechanical properties of R. leguminosarum, cells were first indented with AFM tips to generate force versus distance curves (Figure 1E). The cell spring constant can be calculated directly from the slope (force/distance) of force curves in the linear approach region $(\mathrm{nN} / \mathrm{nm})$. For actively growing cells in media, the $\operatorname{ctp} A$ mutant had a spring constant $(0.0054 \pm 0.0003 \mathrm{~N} / \mathrm{m}(\mathrm{nN} / \mathrm{nm})), \mathrm{k}_{\mathrm{b}}$, two-fold that of wild type $(0.0024 \pm 0.0002 \mathrm{~N} / \mathrm{m})$, indicating that the mutant has a more rigid cell envelope. Spring constants of live cells are lower by an order of magnitude compared to that of fixed samples, indicating a more elastic envelope for fixed cells, as expected [5,6]. The Hertz model, frequently used to fit force approach curves to elastic modulus of the bacterial cell envelope, is best suited to an ideal shell rather than a bacterial cell envelope, which is both anisotropic and heterogeneous, so it was not used to fit this data.

Elastic stiffness (force-displacement) can also be calculated from a nanoscale creep deformation experiment for which the initial force is rapidly applied to the microbe. To understand the response of different cell envelope components to mechanical indentation of the cell surface by the AFM tip, a range of forces were used to generate a series of force approach curves which can be used to plot loading force versus indentation, for which slope corresponds to sample stiffness. For a stiff sample like glass, with no measurable indentation, force versus indentation appears as a vertical line (Figure S3). On the other hand, the $\operatorname{ctp} A$ mutant shows a nonlinear increase in indentation up to a loading force of $4 \mathrm{nN}$, after which it was linear, and appears stiffer than wild type cells, which had an approximately linear response over the entire range of loading force (Figure S3). Interestingly, Figure S4 shows that the $\operatorname{ctp} A$ mutant, compared to wild type, can be indented more easily at smaller loading forces, but less easily once the AFM tip has moved further into the cell at larger loading forces, consistent with a disrupted outer membrane (Figure 2) and a fortified peptidoglycan layer (Table 1). The spring 
constant, $\mathrm{k}_{1}$, of the bacterial cells can also be directly calculated from the ratio between the loading force and indentation depth during the linear response of a cell to loading force (Figure 3). At $2 \mathrm{nN}$, the effective cell spring constants were $0.19 \pm 0.12 \mathrm{~N} / \mathrm{m}$ and $0.25 \pm 0.17 \mathrm{~N} / \mathrm{m}$ for the wild type and ctpA mutant cells, respectively, statistically identical to the values at $4 \mathrm{nN}$, but they gradually increased to $0.27 \pm 0.14 \mathrm{~N} / \mathrm{m}$ and $0.37 \pm 0.21 \mathrm{~N} / \mathrm{m}$, respectively, at $10 \mathrm{nN}$. The ctp $A$ mutant has a significantly $(p<0.05, n=100)$ larger spring constant than wild type at all loading force values, indicating it is stiffer than wild type, consistent with the force curve data. The average value of $k_{1}$ obtained from the creep deformation experiments, however, is 100 fold greater than the cell spring constant measured from force-indentation curves, attributable to the different experimental conditions used to measure $k_{b}$ and $\mathrm{k}_{1}$ : cells on dialysis tubing (soft) in media (hypertonic) with a fast approach $(10 \mu \mathrm{m} / \mathrm{s})$ on the Explorer AFM, versus those on glass (hard) in pure water (hypotonic) with a slower approach $(1 \mu \mathrm{m} / \mathrm{s})$ on the JPK AFM, respectively. Nonetheless, both $\mathrm{k}_{\mathrm{b}}$ and $\mathrm{k}_{1}$ show that the ctpA mutant cells are stiffer than wildtype.

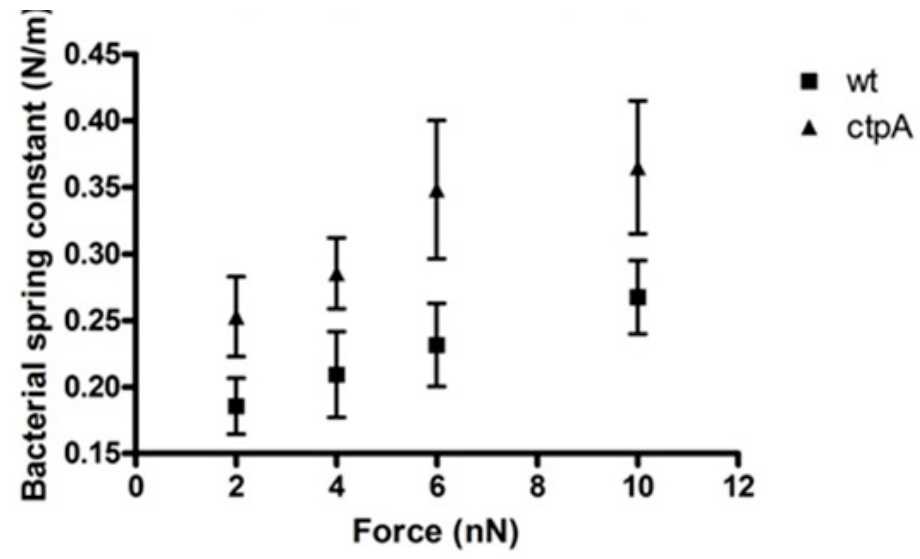

Figure 3. Bacterial spring constant of Rhizobium leguminsarum bv. viciae 3841 (wt) and 3845 (ctpA mutant) as a function of applied force. Spring constants were calculated from the ratio between the loading force and indentation depth during the linear response of a cell to the loading force. Values at 2 and $10 \mathrm{nN}$ are statistically different $(p<0.05)$.

\subsection{Viscoelasticity of the Cell Envelope}

The impact of CtpA on cell envelope viscous and elastic elements was determined from the nanoscale creep deformation experiment (Figure S5A) developed by Lu et al. as a reproducible way of measuring bacterial cell viscoelastic properties [30]. Once a loading force has been rapidly applied to the cell surface (Section 3.3), it is held constant for a given period [47], revealing a time-dependent deformation indicative of a viscoelastic cell envelope (Figure S5B). Since deformation of both strains under a constant loading force for $10 \mathrm{~s}$ proportionally increased as a function of loading force, creep deformations were conducted in the primary and secondary viscoelastic regime to probe linear and nonlinear responses [30]. The four-element Burgers model [47] was used to treat the creep deformation data of both the wild type and $\operatorname{ctp} A$ mutant, generating best-fit values of viscoelastic parameters $\mathrm{k}_{1}, \mathrm{k}_{2}, \eta_{1}$, and $\eta_{2}$ (Table 2 ).

To evaluate the effect of the $\operatorname{ctp} A$ mutation on mechanical response, histograms of $\mathrm{k}_{1}, \mathrm{k}_{2}, \eta_{1}$, and $\eta_{2}$ (Figure 4) were generated at low loading forces ( 2 and $4 \mathrm{nN}$ ). At $2 \mathrm{nN}, \mathrm{k}_{1}$ for the $\operatorname{ctp} A$ mutant is not significantly different from wild type, but interestingly its distribution shifts to a larger value at $4 \mathrm{nN}$ and remains constant from 6 to $10 \mathrm{nN}$ (Figure S6). The $\mathrm{k}_{2}$ and $\eta_{2}$ histogram distributions are narrow at $2 \mathrm{nN}$ for both the wild type and $\operatorname{ctp} A$ mutant (Figure 4), with $\eta_{2}$ starting close to zero, and both broadening and shifting to higher values as a function of loading force (Figure S6). 
Table 2. Best-fit viscoelastic constants of R. leguminsarum bv. viciae 3841 (wt) and 3845 (ctpA) as a function of loading force. $\mathrm{k}_{1}, \mathrm{k}_{2}, \eta_{2}$, and $\eta_{1}$ were fit from the four-element Burgers model [47].

\begin{tabular}{|c|c|c|c|c|c|c|c|c|}
\hline \multirow{2}{*}{$\begin{array}{l}\text { Force } \\
(\mathrm{nN})\end{array}$} & \multicolumn{2}{|c|}{$\begin{array}{c}k_{1} \\
(\mathrm{~N} / \mathrm{m})\end{array}$} & \multicolumn{2}{|c|}{$\begin{array}{c}k_{2} \\
(\mathrm{~N} / \mathrm{m})\end{array}$} & \multicolumn{2}{|c|}{$\begin{array}{c}\eta_{2} \\
(\mathrm{~N} \bullet \mathrm{s} / \mathrm{m})\end{array}$} & \multicolumn{2}{|c|}{$\begin{array}{c}\eta_{1} \\
(\mathrm{~N} \bullet \mathrm{s} / \mathrm{m})\end{array}$} \\
\hline & wt & $\operatorname{ctp} A$ & wt & $\operatorname{ctp} A$ & wt & $\operatorname{ctp} A$ & wt & $\operatorname{ctp} A$ \\
\hline 2 & $\begin{array}{c}0.52 \pm 0.37 \\
n=22\end{array}$ & $\begin{array}{c}0.45 \pm 0.22 \\
n=21\end{array}$ & $\begin{array}{c}0.22 \pm 0.12 \\
n=22\end{array}$ & $\begin{array}{c}0.18 \pm 0.06 \\
n=21\end{array}$ & $\begin{array}{c}0.14 \pm 0.12 \\
n=22\end{array}$ & $\begin{array}{c}0.13 \pm 0.06 \\
n=21\end{array}$ & $\begin{array}{c}5.27 \pm 4.38 \\
n=22\end{array}$ & $\begin{array}{c}5.04 \pm 4.24 \\
n=21\end{array}$ \\
\hline 4 & $\begin{array}{c}0.89 \pm 0.48 \\
n=26\end{array}$ & $\begin{array}{c}0.758 \pm 0.46 \\
n=23\end{array}$ & $\begin{array}{c}0.31 \pm 0.13 \\
n=26\end{array}$ & $\begin{array}{c}0.30 \pm 0.13 \\
n=23\end{array}$ & $\begin{array}{c}0.23 \pm 0.15 \\
n=26\end{array}$ & $\begin{array}{c}0.23 \pm 0.10 \\
n=23\end{array}$ & $\begin{array}{c}8.22 \pm 6.26 \\
n=26\end{array}$ & $\begin{array}{c}7.51 \pm 5.58 \\
n=23\end{array}$ \\
\hline 6 & $\begin{array}{c}0.97 \pm 0.56^{*} \\
n=18\end{array}$ & $\begin{array}{c}1.39 \pm 0.78 * \\
n=23\end{array}$ & $\begin{array}{c}0.37 \pm 0.12 \\
n=18\end{array}$ & $\begin{array}{c}0.41 \pm 0.16 \\
n=23\end{array}$ & $\begin{array}{c}0.27 \pm 0.16 \\
n=18\end{array}$ & $\begin{array}{c}0.33 \pm 0.23 \\
n=23\end{array}$ & $\begin{aligned} 9.95 & \pm 5.66^{*} \\
n & =18\end{aligned}$ & $\begin{array}{c}7.04 \pm 4.50 * \\
n=23\end{array}$ \\
\hline 10 & $\begin{array}{c}1.56 \pm 0.59 \\
n=21\end{array}$ & $\begin{array}{c}1.71 \pm 0.92 \\
n=27\end{array}$ & $\begin{aligned} 0.57 & \pm 0.15 * \\
n & =21\end{aligned}$ & $\begin{array}{c}0.46 \pm 0.21 * \\
n=27\end{array}$ & $\begin{array}{c}0.52 \pm 0.36 \\
n=21\end{array}$ & $\begin{array}{c}0.48 \pm 0.21 \\
n=27\end{array}$ & $\begin{array}{c}12.5 \pm 5.97^{\dagger} \\
n=21\end{array}$ & $\begin{array}{c}6.78 \pm 3.87^{+} \\
n=27\end{array}$ \\
\hline
\end{tabular}

* Student's $t$-test $p<0.05$ (one tail); ${ }^{\dagger}$ Student's $t$-test $p<0.05$ (two tail).
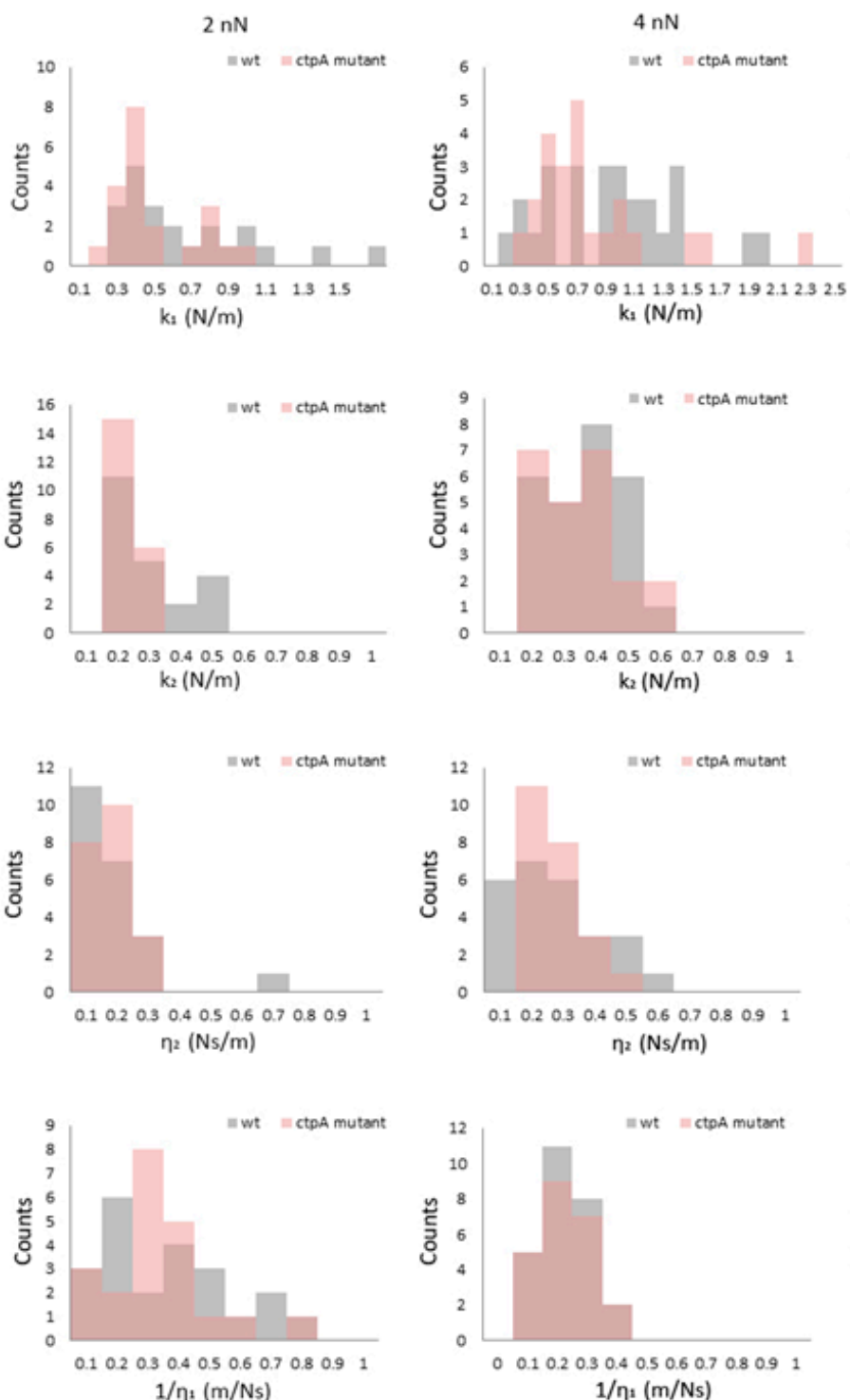

Figure 4. Histograms of viscoelastic parameters $\mathrm{k}_{1}, \mathrm{k}_{2}, \eta_{2}, 1 / \eta_{1}$ for Rhizobium leguminsarum bv. viciae 3841 (wt, grey) and 3845 (ctpA mutant, pink) at low loading forces $(2,4 \mathrm{nN})$ during creep deformation experiments. $k_{1}$ and $k_{2}$ are elastic spring constants, and $\eta_{1}$ and $\eta_{2}$ are viscosity parameters from the Burgers model, in which the Maxwell and Kelvin-Voigt models are connected in series. 


\section{Discussion}

$\operatorname{Ctp} A$, a periplasmic protease, is critical for the maturation of proteins involved in cellular physiology, including cell envelope structure and function [37-39]. In the absence of $\operatorname{ctp} A, R$. leguminosarum has a significantly greater number of detached outer membranes (Figure 2) and consistently less well ordered surfaces than wild type (Figure 1), consistent with a disrupted cell envelope [36,38]. The bacterial cell envelope plays an important role in maintaining cell structure [48,49], as does lipoprotein mediated linkages between the outer membrane and the peptidoglycan layer in Gram-negative cells [50]. Hara et al. attributed the deleterious effects of the Prc (E. coli CtpA homolog) mutation to the potential role of Prc in the maturation of PBP3, responsible for proper peptidoglycan crosslinking [34]. As such we hypothesized that R. leguminosarum PBP could be a substrate of $\operatorname{ctp} A$ and examined the muropeptide component of the cell wall. The higher proportion of the dimeric peptide (GlcNAc-MurNAc-Ala-Glu-meso-DAP-Ala-meso-DAP-Glu-Ala-MurNAc-GlcNAc) in the $\operatorname{ctp} A$ mutant peptidoglycan, indicative of increased crosslinking between peptidoglycan strands, may indeed compensate for the loss of outer membrane integrity associated with the $\operatorname{ctp} A$ gene deletion. However, with no change in the structure of the peptidoglycan peptide bridge for the $\operatorname{ctp} A$ mutant, this means that PBPB and PBPC are still functional in the absence of $c t p A$ in Rhizobium leguminosarum bv. viciae 3841, meaning that either these PBPs are not substrates of $\operatorname{ctp} A$ or there is functional redundancy in the $R$. leguminosarum genome, with more than one C-terminal protease.

KEGG analysis [51] indicates three possible peptidoglycan biosynthetic pathways for Rhizobium leguminosarum bv. viciae 3841, each of which would result in different peptidoglycan peptide bridges. Several enzymes participate in crosslinking GluNAc-MurNAc-Ala-Glu-mDAP-Ala to other muropeptides, including MtgA, PbpC, PbpF, PbpB, and Ala-Ala-carboxylpeptidase. PbpB and PbpC could play major roles in muropeptide cross linking in Rhizobium leguminosarum bv. viciae 3841. Keiler's study [52] of E. coli Tail-specific protease (Tsp (Prc); homolog of $c t p A$ in rhizobia) indicates the greatest preference for Alanine (A), Valine (V), and Serine (S) at the P1 and P1' positions, with second preference to Isoleucine (I), Leucine (L), Arginine (R), and Lysine (K). Thus, it is plausible that PbpC and PbpB from R. leguminosarum bv. viciae 3841 are cleaved by ctpA (Figure S7), but if they are still processed in the absence of $\operatorname{ctp} A$, there must be another Ctp at work. A protein BLAST [53] of the R. leguminosarum genome identified a gene located at the $285,840-305,839 \mathrm{bp}$ position in the pRL12 plasmid encoding a protein with $43 \%$ sequence identity to Tsp (Prc) of E. coli, a potential candidate for Ctp cleavage of $\mathrm{PbpC}$ and $\mathrm{PbpB}$, and functional $\mathrm{Ctp}$ redundancy.

The higher degree of peptide crosslinking in the mutant reinforces its cell wall, likely to compensate for the disrupted outer membrane, as an adaptive response. These major structural differences were expected to have significant mechanical consequences to the local viscoelastic properties of the R. leguminosarum cell envelope, which were examined by monitoring its time-dependent motion in response to a constant compressive force [6]. The nonlinear response often associated with the force curves of Gram-negative bacteria [6] was rarely observed in the wild type R. leguminosarum, implying that the outer membrane and extracellular polysaccharide (EPS) play a minor role in the viscoelastic response of $R$. leguminosarum to an external force. On the contrary, a significant number of force curves from the $\operatorname{ctp} A$ mutant exhibited a nonlinear regime. Shewanella putrefaciens, which has a 20-130 nm capsule on its cell surface, shows a pH-dependent nonlinear deformation by force spectroscopy [54], but our $\operatorname{ctp} A$ mutant produced no additional EPS [38]. The nonlinear regions of force curves from the ctpA mutant were up to 30-40 nm, over which cell deformation would be dominated by the outer layer, most easily attributed to the compromised outer membrane (Figure 2) and further supported by our proteomic data which indicates disruption of outer membrane ABC transporters [39].

On the other hand, elasticity of the bacterial cell envelope is thought to originate from the peptidoglycan network [20]. Isolated sacculi (peptidoglycan layer) from E. coli are flexible and elastic, expanding and contracting without rupture [55], and readily capable of recovering their original shape upon the removal of a loading force [20]. Since glycan strands are very rigid, the elastic properties of the peptidoglycan layer largely originate from the flexibility of the crosslinking muropeptide [56,57]. 
Thus, the increased spring constant of $c t p A$ mutant cells can be reasonably attributed to their higher degree of peptidoglycan crosslinking. Since the outer membrane is compromised in the mutant, a $4 \mathrm{nN}$ deformation appears to reach the peptidoglycan layer underlying the outer membrane, where the mechanical response will be dominated by components of its strand network. The greater number of peptidoglycan subunits and peptide linkages in the $\operatorname{ctp} A$ mutant would be more capable of resisting cell indentation, as reflected by stiffer cells compared to wild type.

The greater $\eta_{1}$ value for wild type compared to that of the $\operatorname{ctp} A$ mutant at the higher loading forces (Figure S6) potentially suggests that the $\operatorname{ctp} A$ mutant has a less viscous cytosol or cytoskeletal network. The delayed elastic response can be attributed to the more liquid-like components in the cell envelope. For example, membranous phospholipid and LPS at the exterior of the bacterial cell envelope are constantly in motion, with mechanical responses comparable to a liquid. Mutants lacking O-antigen side chains of LPS in E. coli have smaller $\eta_{2}$ values but $k_{2}$ values identical to wild type, and in P. aeruginosa smaller $\eta_{2}$ and $k_{2}$ values [30] were rationalized in terms of additional periplasmic water from compromised resistance to hypotonic environments. The $\mathrm{k}_{2}$ and $\eta_{2}$ values of an $E$. coli $l p p$ mutant, lacking cell wall associated lipoproteins, were lower than wild type E. coli, confirming the contribution of lipoproteins to the delayed viscoelastic response [22]. Upon exposure to cationic antimicrobial peptides, $P$. aeruginosa cells released periplasmic proteins accompanied by the entry of water into the periplasm, evidenced by a decrease in both $k_{2}$ and $\eta_{2}$ values [30]. In this study, the increase in $k_{2}$ and $\eta_{2}$ values at higher loading forces $(6-10 \mathrm{nN})$ for both wild type and ctpA mutant cells may indicate the AFM tip beginning to penetrate the cytoskeleton [58] or stiffness contributions from the glass substrate [59].

\section{Conclusions}

This study shows that the absence of C-terminal protease A in Rhizobium leguminosarum gives rise to altered cell envelope properties (AFM), corresponding to a disrupted outer membrane (TEM) and increased crosslinking of the peptidoglycan layer (HPLC-MALDI-TOF). Both the wild type and ctpA mutant exhibit a viscoelastic response to a constant external stress, which during instantaneous elastic deformation are dominated by the outer cell layer at the lowest force load and by the peptidoglycan layer at higher force loads. Thus, the viscoelasticity of the $\operatorname{ctp} A$ mutant reflects both its compromised outer membrane and fortified peptidoglycan layer. Nanoscale creep deformation data provide novel information on the mechanical properties of R. leguminosarum, with the four viscoelastic parameters calculated according to the Burgers model attributable to different components of the bacterial cell envelope.

Supplementary Materials: The following are available online at http://www.mdpi.com/2076-2607/8/9/1421/s1, Table S1: HPLC retention times of major components from the muropeptide purification of the wild type 3841 and $\operatorname{ctp} A$ mutant 3845 strains, Figure S1: HPLC separation of muropeptides of wild type 3841 (Blue) and $c t p A$ mutant 3845 (Red). Optimized HPLC gradient of $1.7-7.8 \%$ acetonitrile with $0.1 \%$ TFA as the organic modifier is shown in green: $0 \%(0-5 \mathrm{~min}), 0-4 \%$ (5-12 $\mathrm{min}), 4 \%$ (12-22 $\mathrm{min}), 4-10 \%$ (22-82 $\mathrm{min}), 10-15 \%$ (82-91 $\mathrm{min})$, and $15-50 \%$ (91-137 $\mathrm{min}$ ) acetonitrile, Figure S2: Representative MALDI-TOF mass spectra for two HPLC purified muropeptides from Rhizobium leguminosarum bv. viciae 3841, Figure S3: Representative approach indentation curves for R. leguminsarum bv. viciae 3841 (wt) and 3845 (ctpA mutant) on PLL-coated glass cover slips under water, Figure S4: Cell indentation of R. leguminsarum bv. viciae 3841 (wt) $(\mathrm{r}=0.998)$ and 3845 (ctpA mutant) $(r=0.997)$ on PLL-coated glass cover slips under water as a function of applied force, Figure S5. (A) Schematic of a creep deformation experiment of a single cell by AFM, in which the AFM tip deforms the cell and gives rise to a Z-piezo displacement and cantilever deflection, used to calculate creep indentation (i). (B) Creep deformation of R. leguminsarum bv. viciae 3841 (wt) and 3845 (ctpA mutant) at loading forces of 2 and $10 \mathrm{nN}$. The solid green line represents best fit to the data for a contact time of $10 \mathrm{~s}$. Inset is a schematic diagram of the Burgers model in which $k_{1}$ and $k_{2}$ are spring constants and $\eta_{1}$ and $\eta_{2}$ are dashpot viscosities, Figure S6. Histograms of viscoelastic parameters $\mathrm{k}_{1}, \mathrm{k}_{2}, \eta_{2}, 1 / \eta_{1}$ for R. leguminsarum bv. viciae 3841 (wt, grey) and 3845 (ctpA mutant, pink) at high $(6,10 \mathrm{nN})$ loading forces during creep deformation experiments. $k_{1}$ and $k_{2}$ are elastic spring constants, and $\eta_{1}$ and $\eta_{2}$ are the viscosity parameters from the Burgers model, in which the Maxwell and Kelvin-Voigt models are connected in series, Figure S7: Potential C-terminal processing sites of $\mathrm{PbpB}$ and $\mathrm{PbpC}$ in Rhizobium leguminosarum bv. viciae 3841, based on substrate preference for Tsp (Prc, ctpA analog) from E. coli. The gene products of $p b p C$ and pbpB in R. leguminosarum are homologous to PBP1C and PBP3 in E. coli, respectively. 
Author Contributions: Conceptualization, D.J. and T.E.S.D.; methodology, D.J. and U.I.; software, D.J.; validation, U.I. and D.J.; formal analysis, D.J.; investigation, D.J. and T.E.S.D.; resources, T.E.S.D.; data curation, D.J.; writing-original draft preparation, D.J.; writing—review and editing, T.E.S.D.; visualization, D.J.; supervision, T.E.S.D.; project administration, T.E.S.D.; funding acquisition, T.E.S.D. All authors have read and agreed to the published version of the manuscript.

Funding: This research was funded by a Natural Sciences and Engineering Research Council (NSERC) Discovery Grant (228206-2012) and Canada Foundation for Innovation Leaders Opportunity Fund to T.E.S.D. U.I. was supported by a NSERC undergraduate student research assistantship and D.J. was partially supported by the Faculty of Graduate Studies and Research, University of Regina. The APC was funded by the University of Regina. This publication was paid for, in part, by the University of Regina President's Publication Fund.

Acknowledgments: We thank Haxia Zhang and Randy Purves for mass spectral analysis, Weyman Chen and Tobias Fürstenhaupt for TEM imaging, John Dutcher for detailed feedback on an early draft of the manuscript and Nicole Hansmeier for helpful advice.

Conflicts of Interest: The authors declare no conflict of interest.

\section{References}

1. Auer, G.K.; Weibel, D.B. Bacterial cell mechanics. Biochemistry 2017, 56, 3710-3724. [CrossRef]

2. Findley, W.N.; Lai, J.S.; Onaran, K. Creep and Relaxation of Nonlinear Viscoelastic Materials with an Introduction to Linear Viscoelasticity; Dover Publications Inc.: New York, NY, USA, 1989.

3. Doyle, R.J.; Marquis, R.E. Elastic, flexible peptidoglycan and bacterial cell wall properties. Trends Microbiol. 1994, 2, 57-60. [CrossRef]

4. Vadillo-Rodriguez, V.; Dutcher, J.R. Viscoelasticity of the cell wall. Soft Matter 2011, 7, 4101-4110. [CrossRef]

5. Bhat, S.V.; Jun, D.; Paul, B.C.; Dahms, T.E.S. Viscoelasticity in Biological Systems: A Special Focus on Microbes. In Viscoelasticity-From Theory to Biological Applications; de Vicente, J., Ed.; InTech: Rijeka, Croatia, 2012; Volume 6, pp. 123-156.

6. Vadillo-Rodriguez, V.; Beveridge, T.J.; Dutcher, J.R. Surface viscoelasticity of individual gram-negative bacterial cells measured using atomic force microscopy. J. Bacteriol. 2008, 190, 4225-4232. [CrossRef]

7. Glauert, A.M.; Thornley, M.J. The topography of the bacterial cell wall. Annu. Rev. Microbiol. 1969, 23, 159-198. [CrossRef]

8. Silhavy, T.J.; Kahne, D.; Walker, S. The bacterial cell envelope. Cold Spring Harb. Perspect. Biol. 2010, 2 , a000414. [CrossRef]

9. Papanastasiou, M.; Orfanoudaki, G.; Koukaki, M.; Kountourakis, N.; Sardis, M.F.; Aivaliotis, M.; Karamanou, S.; Economou, A. The Escherichia coli peripheral inner membrane proteome. Mol. Cell. Proteom. 2013, 12, 599-610. [CrossRef]

10. Schlegel, S.; Hjelm, A.; Baumgarten, T.; Vikström, D.; Gier, J.-W. Bacterial-based membrane protein production. Biochim. Biophys. Acta 2014, 1843, 1739-1749. [CrossRef]

11. Mullineaux, C.W.; Nenninger, A.; Ray, N.; Robinson, C. Diffusion of green fluorescent protein in three cell environments in Escherichia coli. J. Bacteriol. 2006, 188, 3442-3448. [CrossRef]

12. Van Wielink, J.E.; Duine, J.A. How big is the periplasmic space? Trends Biochem. Sci. 1990, 15, $136-137$. [CrossRef]

13. Vollmer, W.; Blanot, D.; De Pedro, M.A. Peptidoglycan structure and architecture. FEMS Microbiol. Rev. 2008, 32, 149-167. [CrossRef] [PubMed]

14. Raetz, C.R.; Guan, Z.; Ingram, B.O.; Six, D.A.; Song, F.; Wang, X.; Zhao, J. Discovery of new biosynthetic pathways: The lipid A story. J. Lipid Res. 2009, 50, S103-S108. [CrossRef]

15. Raetz, C.R.; Whitfield, C. Lipopolysaccharide endotoxins. Annu. Rev. Biochem. 2002, 71, 635-700. [CrossRef]

16. Lerouge, I.; Vanderleyden, J. O-antigen structural variation: Mechanisms and possible roles in animal/plant-microbe interactions. FEMS Microbiol. Rev. 2002, 26, 17-47. [CrossRef]

17. Breedveld, M.W.; Yoo, J.S.; Reinhold, V.N.; Miller, K.J. Synthesis of glycerophosphorylated cyclic beta-(1,2)-glucans by Rhizobium meliloti ndv mutants. J. Bacteriol. 1994, 176, 1047-1051. [CrossRef]

18. Bohin, J.P. Osmoregulated periplasmic glucans in Proteobacteria. FEMS Microbiol. Lett. 2000, 186, 11-19. [CrossRef]

19. Lee., S.; Cho, E.; Jung, S. Periplasmic glucans isolated from Proteobacteria. BMB Rep. 2009, 42, 769-775. [CrossRef] 
20. Koch, A.L.; Woeste, S. Elasticity of the sacculus of Escherichia coli. J. Bacteriol. 1992, 174, 4811-4819. [CrossRef]

21. Chen, N.; Xiang, X.; Saha, R.; Bagley, S.T.; Heiden, P.A. Copolymerization of bacterial cell wall materials to enhance the stability of polyhydroxyalkanoate. Macromol. Chem. Phys. 2012, 313, 2647-2652. [CrossRef]

22. Vadillo-Rodriguez, V.; Schooling, S.R.; Dutcher, J.R. In situ characterization of differences in the viscoelastic response of individual gram-negative and gram-positive bacterial cells. J. Bacteriol. 2009, 191, 5518-5525. [CrossRef]

23. Garcia-Manyes, S.; Sanz, F. Nanomechanics of lipid bilayers by force spectroscopy with AFM: A perspective. Biochim. Biophys. Acta 2010, 1798, 741-749. [CrossRef] [PubMed]

24. Espinosa, G.; Lopez-Montero, I.; Monroy, F.; Langevin, D. Shear rheology of lipid monolayers and insights on membrane fluidity. Proc. Natl. Acad. Sci. USA 2011, 108, 6008-6013. [CrossRef]

25. Picas., L.; Rico, F.; Scheuring, S. Direct measurement of the mechanical properties of lipid phases in supported bilayers. Biophys. J. 2012, 102, L01-L03. [CrossRef]

26. Gambin, Y.; Lopez-Esparza, R.; Reffay, M.; Sierecki, E.; Gov, N.S.; Genest, M.; Hodges, R.S.; Urbach, W. Corrections to the Saffman-Delbruck mobility for membrane bound proteins. Proc. Natl. Acad. Sci. USA 2006, 103, 2098-2102. [CrossRef]

27. Jeon, J.; Voth, G.A. The dynamic stress responses to area change in planar lipid bilayer membranes. Biophys. J. 2005, 88, 1104-1119. [CrossRef]

28. Jauffred, L.; Callisen, T.H..; Oddershede, L.B. Visco-elastic membrane tethers extracted from Escherichia coli by optical tweezers. Biophys. J. 2007, 93, 4068-4075. [CrossRef]

29. Touhami, A.; Nysten, B.; Dufrêne, Y.F. Nanoscale mapping of the elasticity of microbial cells by atomic force microscopy. Langmuir 2003, 19, 4539-4543. [CrossRef]

30. Lu., S.; Walters, G.; Parg, R.; Dutcher, J.R. Nanomechanical response of bacterial cells to cationic antimicrobial peptides. Soft Matter 2014, 10, 1806-1815. [CrossRef]

31. Zahran, H.H. Rhizobium-legume symbiosis and nitrogen fixation under severe conditions and in an arid climate. Microbiol. Mol. Biol. Rev. 1999, 63, 968-989. [CrossRef]

32. Vriezen, J.A.C.; de Bruijn, F.J.; Nüsslein, K. Responses of rhizobia to desiccation in relation to osmotic stress, oxygen, and temperature. Appl. Environ. Microbiol. 2007, 73, 3451-3459. [CrossRef]

33. Long, S.R. Rhizobium-legume nodulation: Life together in the underground. Cell 1989, 56, $203-214$. [CrossRef]

34. Hara, H.; Yamamoto, Y.; Higashitani, A.; Suzuki, H.; Nishimura, Y. Cloning, mapping, and characterization of the Escherichia coli prc gene, which is involved in C-terminal processing of penicillin-binding protein 3. J. Bacteriol. 1991, 173, 4799-4813. [CrossRef] [PubMed]

35. Seoane, A.; Sabbaj, A.; McMurry, L.M.; Levy, S.B. Multiple antibiotic susceptibility associated with inactivation of the prc gene. J. Bacteriol. 1992, 174, 7844-7847. [CrossRef]

36. Wang, C.Y.; Wang, S.W.; Huang, W.C.; Kim, K.S.; Chang, N.S.; Wang, Y.H.; Wu, M.H.; Teng, C.H. Prc contributes to Escherichia coli evasion of classical complement-mediated serum killing. Infect. Immun. 2012, 80, 3399-3409. [CrossRef]

37. Gilbert, K.B.; Vanderlinde, E.M.; Yost, C.K. Mutagenesis of the carboxy terminal protease CtpA decreases desiccation tolerance in Rhizobium leguminosarum. FEMS Microbiol. Lett. 2007, 272, 65-74. [CrossRef]

38. Dong, J.; Signo, K.S.L.; Vanderlinde, E.M.; Yost, C.K.; Dahms, T.E.S. Atomic force microscopy of a ctpA mutant in Rhizobium leguminosarum reveals surface defects linking CtpA function to biofilm formation. Microbiology 2011, 157, 3049-3058. [CrossRef]

39. Jun, D.; Minic, Z.; Vanderlinde, E.M.; Bhat, S.V.; Yost, C.K.; Babu, M.; Dahms, T.E.S. Metabolic adaptation of a C-terminal protease A-deficient Rhizobium leguminosarum in response to loss of nutrient transport. Front. Microbiol. 2018, 8, 2617. [CrossRef]

40. Johnston, A.W.; Beringer, J.E. Identification of the rhizobium strains in pea root nodules using genetic markers. J. Gen. Microbiol. 1975, 87, 343-350. [CrossRef]

41. Vincent, J.M. A Manual for the Practical Study of Root-Nodule Bacteria; Blackwell Scientific: Oxford, UK, 1970.

42. Pisabarro, A.G.; de Pedro, M.A.; Vazquez, D. Structural modifications in the peptidoglycan of Escherichia coli associated with changes in the state of growth of the culture. J. Bacteriol. 1985, 161, 238-242. [CrossRef]

43. Zhang, H.; Olson, D.J.H.; Van, D.; Purves, R.W.; Smith, M.A. Rapid identification of 5 triacylglycerol-estolides in plant and fungal oils. Ind. Crops Prod. 2012, 37, 186-194. [CrossRef] 
44. Paul, B.C.; Ma, H.; Snook, L.A.; Dahms, T.E.S. High spatial resolution surface imaging and analysis of fungal cells using AFM and force spectroscopy. In Laboratory Protocols in Fungal Biology; Gupta, V.K., Tuohy, M.G., Ayyachamy, M., Turner, K.M., O’Donovan, A., Eds.; Springer: New York, NY, USA, 2013; pp. 151-160.

45. Cleveland, J.P.; Manne, S.; Bocek, D.; Hansma, P.K. A nondestructive method for determining the spring constant of cantilevers for scanning force microscopy. Rev. Sci. Instrum. 1993, 64, 403-405. [CrossRef]

46. Lévy, R.; Maaloum, M. Measuring the spring constant of atomic force microscope cantilevers: Thermal fluctuations and other methods. Nanotechnology 2001, 13, 33-37. [CrossRef]

47. Geiss, P. Creep load conditions. In Handbook of Adhesion Technology; da Silva, L.M., Ãchsner, A., Adams, R., Eds.; Springer: Berlin/Heidelberg, Germany, 2011; Volume 8, pp. 875-902.

48. Baldwin, W.W.; Sheu, M.J.; Bankston, P.W.; Woldringh, C.L. Changes in buoyant density and cell size of Escherichia coli in response to osmotic shocks. J. Bacteriol. 1988, 170, 452-455. [CrossRef] [PubMed]

49. Koch, A.L. Shrinkage of growing Escherichia coli cells by osmotic challenge. J. Bacteriol. 1984, 159, $919-924$. [CrossRef] [PubMed]

50. Sonntag, I.; Schwarz, H.; Hirota, Y.; Henning, U. Cell envelope and shape of Escherichia coli: Multiple mutants missing the outer membrane lipoprotein and other major outer membrane proteins. J. Bacteriol. 1978, 136, 280-285. [CrossRef] [PubMed]

51. Kanehisa, M.; Furumichi, M.; Tanabe, M.; Sato, Y.; Morishima, K. KEGG: New perspectives on genomes, pathways, diseases and drugs. Nucleic Acids Res. 2017, 45, D353-D361. [CrossRef]

52. Keiler, K.C.; Sauer, R.T. Identification of Active Site Residues of the Tsp Protease. J. Biol. Chem. 1995, 270, 28864-28868. [CrossRef]

53. Altschul, S.F.; Gish, W.; Miller, W.; Myers, E.W.; Lipman, D.J. Basic local alignment search tool. J. Mol. Biol. 1990, 215, 403-410. [CrossRef]

54. Gaboriaud, F.; Bailet, S.; Dague, E.; Jorand, F. Surface structure and nanomechanical properties of Shewanella putrefaciens bacteria at two $\mathrm{pH}$ values (4 and 10) determined by atomic force microscopy. J. Bacteriol. 2005, 187, 3864-3868. [CrossRef]

55. Yao, X.; Jericho, M.; Pink, D.; Beveridge, T. Thickness and elasticity of gram-negative murein sacculi measured by atomic force microscopy. J. Bacteriol. 1999, 181, 6865-6875. [CrossRef]

56. Barnickel, G.; Labischinski, H.; Bradaczek, H.; Giesbrecht, P. Conformational energy calculation on the peptide part of murein. Eur. J. Biochem. 1979, 95, 157-165. [CrossRef]

57. Labischinski, H.; Barnickel, G.; Bradaczek, H.; Giesbrecht, P. On the secondary and tertiary structure of murein. Low and medium-angle $X$-ray evidence against chitin-based conformations of bacterial peptidoglycan. Eur. J. Biochem. 1979, 95, 147-155. [CrossRef] [PubMed]

58. Mayer, F. Cytoskeletons in prokaryotes. Cell Biol. Int. 2003, 27, 429-438. [CrossRef]

59. Smolyakov, G.; Formosa-Dague, C.; Severac, C.; Duval, R.E.; Dague, E. High speed indentation measures by FV, QI and QNM introduce a new understanding of bionanomechanical experiments. Micron 2016, 85, 8-14. [CrossRef] [PubMed]

(C) 2020 by the authors. Licensee MDPI, Basel, Switzerland. This article is an open access article distributed under the terms and conditions of the Creative Commons Attribution (CC BY) license (http://creativecommons.org/licenses/by/4.0/). 